\title{
The change of QRS duration after pulmonary valve replacement in patients with repaired tetralogy of Fallot and pulmonary regurgitation
}

\author{
Yuni Yun, MD, Yeo Hyang Kim, MD, PhD, Jung Eun Kwon, MD \\ Division of Pediatric Cardiology, Department of Pediatrics, Kyungpook National University Children's Hospital, School of Medicine, Kyungpook National University, \\ Daegu, Korea
}

Purpose: This study aimed to analyze changes in QRS duration and cardiothoracic ratio (CTR) following pulmonary valve replacement (PVR) in patients with tetralogy of Fallot (TOF).

Methods: Children and adolescents who had previously undergone total repair for TOF $(n=67$; median age, 16 years) who required elective PVR for pulmonary regurgitation and/or right ventricular out tract obstruction were included in this study. The QRS duration and CTR were measured pre- and postoperatively and postoperative changes were evaluated.

Results: Following PVR, the CTR significantly decreased (pre-PVR $57.2 \% \pm 6.2 \%$, post-PVR $53.8 \% \pm$ $5.5 \%, P=0.002$ ). The postoperative QRS duration showed a tendency to decrease (pre-PVR 162.7 \pm 26.4 msec, post-PVR 156.4 $\pm 24.4 \mathrm{msec}, P=0.124)$. QRS duration was greater than $180 \mathrm{msec}$ in 6 patients prior to PVR. Of these, 5 patients showed a decrease in QRS duration following PVR; QRS duration was less than 180 msec in 2 patients, and QRS duration remained greater than $180 \mathrm{msec}$ in 3 patients, including 2 patients with diffuse postoperative right ventricular outflow tract hypokinesis. Six patients had coexisting arrhythmias before PVR; 2 patients, atrial tachycardia; 3 patients, premature ventricular contraction; and 1 patient, premature atrial contraction. None of the patients presented with arrhythmia following PVR.

Conclusion: The CTR and QRS duration reduced following PVR. However, QRS duration may not decrease below 180 msec after PVR, particularly in patients with right ventricular outflow tract hypokinesis. The CTR and ECG may provide additional clinical information on changes in right ventricular volume and/or pressure in these patients.

Key words: Tetralogy of Fallot, Heart valve prosthesis implantation, Electrocardiography

\section{Introduction}

Tetralogy of Fallot (TOF) is the most common cyanotic congenital heart disease, with an incidence rate of 5\%-7\%. ${ }^{1)}$ Characteristic anatomic features include (1) right ventricular outflow tract (RVOT) stenosis, (2) ventricular septal defect, (3) overriding aortic root, and (4) right ventricular hypertrophy. $^{2-4)}$

Total correction of TOF eliminates the RVOT stenosis and closes the interventricular septal defect. Patients who underwent successful corrective surgery generally are symptomfree and show good recovery, but pulmonary regurgitation (PR) may remain after relief of RVOT stenosis. ${ }^{1,4)}$ Although PR severity may vary, severe or prolonged PR can in turn lead to RV dilation and functional decline, hypokinesis, and ventricular arrhythmia. ${ }^{1,5-7)}$ These changes require long-term regular follow-up using chest X-ray, electrocardiogram (ECG), and
Corresponding author: Jung Eun Kwon, MD Department of Pediatrics, School of Medicine, Kyungpook National University, 680 Gukchaebosang-ro, Jung-gu, Daegu 41944, Korea Tel: +82-53-200-5704

Fax: +82-53-425-6683

E-mail: lovecello623@gmail.com https://orcid.org/0000-0001-6608-3089

Received: 9 July, 2018

Revised: 20 October, 2018

Accepted: 24 October, 2018
Copyright (C) 2018 by The Korean Pediatric Society

This is an open-access article distributed under the terms of the Creative Commons Attribution NonCommercial License (http://creativecommons.org/ licenses/by-nc/4.0/) which permits unrestricted noncommercial use, distribution, and reproduction in any medium, provided the original work is properly cited. 
echocardiography. ECG and chest X-ray can show QRS duration $>180$ msec and increased cardiothoracic ratio (CTR), respectively.

Pulmonary valve replacement (PVR) for patients with repaired TOF improves signs of heart failure caused by chronic volume overload of the RV. It can decrease RV volume and size, eliminate the propensity for arrhythmia, and decrease the risk of sudden cardiac death. During regular follow-up after PVR, not only echocardiography but also ECG and chest X-ray may show these changes. ${ }^{8)}$

This study investigated the changes of QRS duration and CTR after PVR using ECG and chest X-ray in patients with TOF and severe PR.

\section{Materials and methods}

\section{Patients}

Among patients who was diagnosed with TOF prior to age 1 and underwent total correction, 67 receiving regular follow-up between January 2005 and February 2015 for PR or RVOT stenosis were included in the analysis. Enrolled patients were divided into 2 groups such as PVR group and non-PVR group according to need for PVR due to severe PR.

Severe PR were examined using echocardiography defined as abnormal pulmonary valve (distorted or absent leaflets, or annular dilation), RV enlargement, paradoxical septal motion, Color jet which fills RVOT, and/or continuous wave jet density and contour (dense laminar flow with steep deceleration slope and abrupt termination). ${ }^{9,10)}$

Total correction of TOF involved median sternotomy, followed by patch closure of the interventricular septum through an RV or right atrial approach under cardiopulmonary bypass and circulatory arrest, as well as enlargement of the RV outflow tract and stenotic pulmonary arteries. ${ }^{11)}$ The timing of PVR for severe PR was determined via 2-dimensional echocardiography and cardiac catheterization. For male patients, mechanical valve was chosen first.

A 12-lead ECG was performed preoperatively and 1 year postoperatively, and the QRS duration was analyzed. The ECG was performed at a paper speed of $25 \mathrm{~mm} / \mathrm{sec}$, and QRS duration was defined as the interval from the beginning of the $Q$ wave to the end of the $S$ wave, corresponding to the time from ventricular depolarization to activation of all parts of the heart. The longest QRS duration was used for this analysis.

The CTR was calculated from the chest X-ray performed at the time of admission for PVR and 1 year postoperatively.

Patient information was retrieved and evaluated with the approval of the medical records department and Institutional Review Board at Kyungpook National University Hospital (approval number: 2016-11-019).

\section{Statistical analysis}

All statistical analyses were performed using IBM SPSS Statistics ver. 21.0 (IBM Co., Armonk, NY, USA), and the results were indicated as mean \pm standard deviation or median. Comparative analysis was performed using Student $t$ test, and a $P$ value of less than 0.05 was defined as statistically significant.

\section{Results}

\section{Demographic data}

Of 67 patients analyzed, 22 underwent PVR (Table 1). Sixteen patients (16 of 22, 73\%) needed transannular (TAP) patch insertion at the time of initial TOF correction. Patients were followed up for a median of 14.5 years (range, 6-22 years) from the time of initial TOF correction to PVR. The median age at the time of PVR was 16 years (range, 9-30 years). Eleven patients (11 of 22, 50\%) showed RV hypertrophy and diffuse RV hypokinesis on pre-PVR computed tomography and echocardiography, and 1 had an RVOT aneurysm.

The main reason for PVR was severe PR in 20 and severe PR accompanied by pulmonary stenosis (PS) in 2. Mechanical and tissue valve were used for PVR in 8 (8 of 22, 36\%) and 14 (14 of 22, 64\%), respectively. Eleven patients ( 11 of 22, 50\%) needed addition procedures with PVR; peripheral pulmonary angioplasty in 6, tricuspid valve repair in 4, and maze operation for atrial tachycardia (AT) in 1. The median duration of follow-up after PVR was 3.9 years (range, 0.9-8.3 years).

The median age of the 45 patients who did not undergo PVR was 13 years at the latest follow-up (range, 8-23). There were 23 patients (23 of 45, 51\%) with TAP at the time of initial TOF correction. The median duration of follow-up after initial total TOF correction was 11.2 years (range, 6.7-23 years).

Table 1. Comparison of the PVR group with the non-PVR group

\begin{tabular}{lcc}
\hline Variable & PVR $(\mathrm{n}=22)$ & Non-PVR $(\mathrm{n}=45)$ \\
\hline Age (yr) & $16(9-30)$ & $13(8-23)$ \\
Male sex & $10(45)$ & $23(51)$ \\
TAP & $16(73)$ & $23(51)$ \\
PR without PS & $20(91)$ & $37(82)$ \\
PR with PS & $2(9)$ & $8(18)$ \\
Mechanical valve replacement & $8(36)$ & - \\
Tissue valve replacement & $14(64)$ & - \\
Peripheral pulmonary angioplasty & $6(27)$ & - \\
Tricuspid valve repair & $4(18)$ & - \\
Maze operation & $1(5)$ & - \\
Follow-up (from first total correction of TOF) & $14.5(6-22)$ & $11.2(6.7-23)$ \\
\hline
\end{tabular}

Values are presented as median (range) or number (\%).

PVR, pulmonary valve replacement; TAP, transannular patch; PR, pulmonary regurgitation; PS, pulmonary stenosis; TOF, tetralogy of Fallot. 


\section{Change in CTR}

CTR in the PVR and non-PVR groups is shown in Table 2. CTR was significantly different between the PVR and non-PVR group $(P=0.001)$, and reduced from pre-PVR to post-PVR $(P=0.002)$.

\section{Change in QRS duration}

QRS duration was significantly different between the PVR and no-PVR group (Table 2) $(P=0.001)$. Compared with pre-PVR QRS duration, post-PVR QRS duration was decreased, but not significantly $(P=0.124)$.

There were 6 patients with pre-PVR QRS duration $>180$ msec (Table 3). Among them, 5 patients showed reduction of QRS duration after PVR; post-PVR QRS duration $<180$ msec in 2 and postPVR QRS duration >180 msec in 3. There was 1 patient with prePVR and post-PVR QRS duration $>180$ msec without change after PVR. Of the 4 patients with post-PVR QRS duration >180 msec, 2 had diffuse RVOT hypokinesis postoperatively.

There were 16 patients with pre-PVR QRS duration $<180$ msec. Among them, 6 patients showed reduction of QRS duration after PVR and had post-PVR QRS duration $<180$ msec. Although 7 patients showed increase or no change of post-PVR QRS duration, they had post-PVR QRS duration $<180$ msec. Three patients with pre-PVR QRS duration < 180 msec showed post-PVR QRS duration $>180$ msec. They already had trifascicular block, and needed redoPVR or concurrent pulmonary angioplasty at the time of PVR.

Table 2. Comparison of pre- and post-PVR QRS duration and CTR change

\begin{tabular}{lcc}
\hline Variable & PVR $(n=22)$ & Non-PVR $(n=45)$ \\
\hline Preoperative & & \\
$\quad$ CTR (\%) & $57.2 \pm 6.2^{*}$ & $51.7 \pm 5.21$ \\
QRS duration (msec) & $162.7 \pm 26.4^{*}$ & $124.1 \pm 31.1$ \\
Postoperative & & \\
CTR (\%) & $53.8 \pm 5.5^{\dagger}$ & - \\
QRS duration (msec) & $156.4 \pm 24.4$ & - \\
\hline
\end{tabular}

Values are presented as mean \pm standard deviation

${ }^{*} P<0.001$ in PVR versus Non-PVR. ${ }^{\dagger} P<0.05$ preoperative vs. postoperative in PVR

PVR, pulmonary valve replacement; CTR, cardiothoracic ratio.

Table 3. Comparison of pre- and post-PVR QRS duration (QRSd)

\begin{tabular}{lcccc}
\hline $\begin{array}{l}\text { Pre-PVR QRSd } \\
(\mathrm{msec})\end{array}$ & $\begin{array}{c}\text { Post-PVR QRSd } \\
(\mathrm{msec})\end{array}$ & $\begin{array}{c}\text { Reduction } \\
(\mathrm{n}=11)\end{array}$ & $\begin{array}{c}\text { Increase } \\
(\mathrm{n}=4)\end{array}$ & $\begin{array}{c}\text { No change } \\
(\mathrm{n}=7)\end{array}$ \\
\hline$>180$ & $>180$ & 3 & - & 1 \\
& $<180$ & 2 & - & - \\
$<180$ & $>180$ & - & 3 & - \\
& $<180$ & 6 & 1 & 6
\end{tabular}

Values are presented as number.

PVR, pulmonary valve replacement.

\section{Change in arrhythmias}

Six patients showed coexisting arrhythmias before PVR. There were AT in 2, premature ventricular contractions (PVCs) in 3, and nonconducted premature atrial contractions (PACs) and left ventricular systolic dysfunction in 1.

One patient with PVC showed pre-PVR QRS duration > 180 msec and post-PVR QRS duration < 180 msec. Four patients (AT in 2 and PVC in 2) showed pre-PVR QRS duration $<180$ msec and reduction of post-PVR QRS duration. One patient with PAC did not show any change between pre-PVR and post-PVR.

There was no patient with arrhythmia confirmed by ECG after PVR, and no reported cases of arrhythmia recurrence by holter monitoring and symptoms, chest pain, or additional surgery during follow-up.

\section{Discussion}

We hypothesized that increased RV volume in repaired TOF and severe PR would decrease after PVR, and CTR on chest X-ray and QRS duration on ECG would reflect these changes. From the present study, we found that post-PVR CTR on chest X-ray showed significant decrease. In addition, PVR could make reduction of QRS duration for patients with pre-PVR QRS duration >180 msec and improvement of arrhythmia, although some patients still showed post-PVR QRS duration >180 msec.

ECG can be a simple yet clinically relevant indicator for RV function and long-term prognosis in patients who have undergone TOF correction. In previous studies, QRS duration on ECG was related to the degree of RV hypertrophy, arrhythmia, and sudden death. In particular, QRS duration >180 msec was associated with ventricular tachycardia, RV dilatation, and sudden death. ${ }^{1,4,10)}$ Moreover, patients who underwent surgery for TOF showed increased long-term mortality due to ventricular arrhythmia. ${ }^{12)}$

Previous studies reported that patients with severe PR who underwent surgical TOF correction showed post-PVR improvement in arrhythmia as well as a decrease in QRS duration >180 msec. ${ }^{13,14)}$ However, recent studies show that the relationship between PVR and QRS duration is not clear. ${ }^{5,15,16)}$ QRS duration $>180$ msec prior to PVR that did not decrease after PVR was associated with symptomatic heart failure, repeat PVR, ventricular arrhythmia, and death. ${ }^{17)}$ The present study showed that PVR was related with decrease in postPVR QRS duration in 50\% of patients and resolution of arrhythmia. However, 67\% of patients with pre-PVR QRS duration >180 msec had still post-PVR QRS duration $>180$ msec. They showed pre-PVR CTR greater than $60 \%$, or decreased cardiac function associated with ventricular arrhythmia and likely did not show normal recovery of RV function or volume postoperatively.

The results of the present and previous studies indicate that despite elimination of PR and decreased RV volume loading after 
PVR, severe and prolonged PR leads to irreversible damage to RV myocytes due to volume overload and inhibits recovery of RV function to a normal level.

Another study proposed that prolonged QRS duration is related to infundibular disease due to local damage from TOF, rather than RV dysfunction. ${ }^{18)}$ A damaged RVOT affects postoperative ventricular remodeling, RV function, and dyssynchrony of ventricular contraction and causes heterogeneous conduction. This can lead to persistent risk of arrhythmia in TOF patients with cardiomyocyte damage and tissue remodeling due to preoperative cyanosis, ventricular pressure, or volume loading. ${ }^{15,16,19)}$ In other words, PVR plays a role in decreasing RV volume loading but does not alleviate RVOT pathology, therefore may not decrease QRS duration. ${ }^{5,16,19,20)}$ In the present study, patients who showed increase or no change of postPVR QRS duration underwent infundibulectomy and TAP. They showed RV hypertrophy, severe PR, and diffuse RV hypokinesis on preoperative computed tomography and echocardiography, and 1 had an RVOT aneurysm. Therefore, current TOF corrective surgery is focused on the RV infundibulum and pulmonary valve preservation. This is probably because these are important factors leading to arrhythmia and sudden death, as shown in this study.

The limitations of this study include the small sample size and retrospective study design. We did not perform RV volume measurement using cardiac magnetic resonance imaging (MRI) or 3-dimensional echocardiography routinely. It was not able to compare results between MRI or echocardiogram and CTR and ECG. The possibility of bias due to the timing of PVR after TOF correction and remnant pathology or symptoms cannot be ignored.

In conclusion, CTR and QRS duration tend to reduce after PVR. However, the absence of a reduction in QRS duration $<180 \mathrm{msec}$ after PVR may be occurred, especially in patients with RVOT hypokinesis. Although cardiac MRI is preferred for the analysis of RV volume and function in patients with repaired TOF, CTR on chest Xray and QRS duration on 12 lead ECG are easily evaluated in clinical practice, and these may provide additional clinical information reflecting changes in RV volume and/or pressure.

\section{Conflicts of interest}

No potential conflict of interest relevant to this article was reported.

\section{References}

1. Park IS. An atlas and text of congenital heart disease. Seoul: Korea Textbook Publishing Co., 2008.

2. Apitz C, Webb GD, Redington AN. Tetralogy of Fallot. Lancet 2009; 374:1462-71.

3. Van Praagh R. The first Stella van Praagh memorial lecture: the history and anatomy of tetralogy of Fallot. Semin Thorac Cardiovasc Surg Pediatr Card Surg Annu 2009:19-38.

4. Starr JP. Tetralogy of fallot: yesterday and today. World J Surg 2010; 34:658-68.

5. Gatzoulis MA, Balaji S, Webber SA, Siu SC, Hokanson JS, Poile C, et al. Risk factors for arrhythmia and sudden cardiac death late after repair of tetralogy of Fallot: a multicentre study. Lancet 2000;356: 975-81.

6. Tzemos N, Harris L, Carasso S, Subira LD, Greutmann M, Provost Y, et al. Adverse left ventricular mechanics in adults with repaired tetralogy of Fallot. Am J Cardiol 2009;103:420-5.

7. Gatzoulis MA, Till JA, Somerville J, Redington AN. Mechanoelectrical interaction in tetralogy of Fallot. QRS prolongation relates to right ventricular size and predicts malignant ventricular arrhythmias and sudden death. Circulation 1995;92:231-7.

8. Shiokawa Y, Sonoda H, Tanoue Y, Nishida T, Nakashima A, Tominaga R. Pulmonary valve replacement long after repair of tetralogy of Fallot. Gen Thorac Cardiovasc Surg 2012;60:341-4.

9. Nishimura RA, Otto CM, Bonow RO, Carabello BA, Erwin JP 3rd, Guyton RA, et al. 2014 AHA/ACC guideline for the management of patients with valvular heart disease: a report of the American College of Cardiology/American Heart Association Task Force on Practice Guidelines. J Am Coll Cardiol 2014;63:e57-185.

10. Zoghbi WA, Enriquez-Sarano M, Foster E, Grayburn PA, Kraft CD, Levine RA, et al. Recommendations for evaluation of the severity of native valvular regurgitation with two-dimensional and Doppler echocardiography. J Am Soc Echocardiogr 2003;16:777-802.

11. Choi JY. Long-term problems in patients with totally repaired tetralogy of Fallot - a new paradigm for late management. Korean J Pediatr 2003;46:627-34.

12. Friedli B. Electrophysiological follow-up of tetralogy of fallot. Pediatr Cardiol 1999;20:326-30.

13. van Huysduynen BH, van Straten A, Swenne CA, Maan AC, van Eck HJ, Schalij MJ, et al. Reduction of QRS duration after pulmonary valve replacement in adult Fallot patients is related to reduction of right ventricular volume. Eur Heart J 2005;26:928-32.

14. Hooft van Huysduynen B, Henkens IR, Swenne CA, Oosterhof T, Draisma HH, Maan AC, et al. Pulmonary valve replacement in tetralogy of Fallot improves the repolarization. Int J Cardiol 2008;124: 301-6.

15. Cheung EW, Wong WH, Cheung YF. Meta-analysis of pulmonary valve replacement after operative repair of tetralogy of fallot. Am J Cardiol 2010;106:552-7.

16. Geva T. Repaired tetralogy of Fallot: the roles of cardiovascular magnetic resonance in evaluating pathophysiology and for pulmonary valve replacement decision support. J Cardiovasc Magn Reson 2011; 13:9.

17. Scherptong RW, Hazekamp MG, Mulder BJ, Wijers O, Swenne CA, van der Wall EE, et al. Follow-up after pulmonary valve replacement in adults with tetralogy of Fallot: association between QRS duration and outcome. J Am Coll Cardiol 2010;56:1486-92.

18. Uebing A, Gibson DG, Babu-Narayan SV, Diller GP, Dimopoulos K, Goktekin 0, et al. Right ventricular mechanics and QRS duration in patients with repaired tetralogy of Fallot: implications of infundibular disease. Circulation 2007;116:1532-9.

19. Villafañe J, Feinstein JA, Jenkins KJ, Vincent RN, Walsh EP, Dubin AM, et al. Hot topics in tetralogy of Fallot. J Am Coll Cardiol 2013;62: 2155-66.

20. Khairy P, Landzberg MJ, Gatzoulis MA, Lucron H, Lambert J, Marçon $\mathrm{F}$, et al. Value of programmed ventricular stimulation after tetralogy of fallot repair: a multicenter study. Circulation 2004;109:1994-2000. 